\title{
Occupational Exposure to Non-Ionizing radiation. Main effects and criteria for health surveillance of workers according to the European Directives
}

\author{
Alberto Modenese \\ Dept. of Biomedical, Metabolic and \\ Neural Sciences \\ University of Modena \& Reggio Emilia \\ Modena, Italy \\ alberto.modenese@unimore.it
}

\author{
Fabriziomaria Gobba \\ Dept. of Biomedical, Metabolic and \\ Neural Sciences \\ University of Modena \& Reggio Emilia \\ Modena, Italy \\ fabriziomaria.gobba@unimore.it
}

\begin{abstract}
Occupational exposure to Non-Ionizing radiation (NIR), including Electromagnetic fields (EMF) and Optical radiation (OR), is almost ubiquitous. EMF may induce various effects: in the case of direct short term effects, static and low-frequency fields interact with the biological tissues through the induction of currents, while high frequency fields through thermal mechanisms. EMF can also induce indirect effects, as interference, causing a specific risk e.g. in workers with active medical devices as pacemakers. The induction of various long term effects has also been proposed, but up now data supporting a causal effect are considered insufficient by almost all authoritative international agencies. Moving to OR, sources can be artificial (incoherent or coherent in the case of LASER) or natural; the main source of occupational OR exposure is natural: the Sun, exposing millions of outdoor workers worldwide. The main targets of $O R$ effects are the skin and the eye. Among OR bands, the ultraviolet component is of particular relevance, inducing photochemical alterations in human cells that can cause both acute and long term effects as burns and skin cancers or cataract. For all workers NIR risk should be evaluated and, in case of significant risk, an adequate health surveillance (HS) should be implemented, also considering the possible presence of workers with conditions inducing a higher susceptibility to the risk, as subjects with active medical devices for EMF or subjects with a fair skin photo-type or eye alterations as aphakia or aniridia for OR. Aims of HS of occupational NIR exposure are the prevention and early detection of related health effects. The appropriate specific HS content depends on the NIR band(s) and on the specific work activities but, in general, at least a screening of the conditions inducing a particular risk and an active seeking of symptoms possibly induced by exposure should be performed before of the employment, and periodically repeated.
\end{abstract}

Keywords - non-ionizing radiation, occupational exposure, health surveillance, optical radiation, electromagnetic fields

\section{INTRODUCTION}

In recent years, there has been a constant development of technologies inducing a progressive increase of the occupational exposure in the workplaces to various sources of non-ionizing radiation (NIR), including both electromagnetic fields (EMF) and optical radiation (OR) [1, 2]. Among the main examples there are the development of EMF applications in many settings, involving the whole spectrum from static fields (e.g. the increasing diffusion of MRI applications), to extremely-low frequency fields (ELF) (e.g. new medical applications as transcranial magnetic stimulation or high powered pulses for cancer therapy), to the new Ultra-High Frequency Radiofrequency Identification - RFID - systems or new mobile communication and internet technologies as 5G [2]. For OR possible examples are the new powerful technologies developed for LASERs as well as the innovative LED technologies that have determined a revolution of the ways of illuminating the environments [1]. But, on the other hand, the occupational risk related to the most ancient source of OR, solar radiation, is still somewhat not adequately recognized, if not neglected, even if exposure involves millions of outdoor workers in the world, and the potential health impact e.g. in terms of skin cancers or cataracts related to the ultraviolet radiation (UVR) component is certainly huge $[3,4]$.

In this manuscript we present an overview of the occupational risk related to NIR exposure in the workplaces, also addressing the issues related to the existence of group of workers having a specific higher susceptibility to NIR ("workers at particular risk"), and the problem of an effective health surveillance (HS) for these workers.

\section{OPTICAL RADIATION}

\section{A. Occupational Optical Radiation exposure and health}

Optical radiation (OR) is composed by (Fig. 1):

- UVR: UVC (wavelength- $\lambda=100-280 \mathrm{~nm}), \operatorname{UVB}(\lambda=$ 280-315 nm), UVA $(\lambda=315-400 \mathrm{~nm})$;

- Visible radiation $(\lambda=400-780 \mathrm{~nm})$;

- Infrared radiation (IR): IR-A $(\lambda=780-1400 \mathrm{~nm})$, IR-B $(\lambda=1400-3000 \mathrm{~nm})$, and IR-C $(\lambda=1 \mathrm{~mm}-3000 \mathrm{~nm})$.

These spectral regions have different penetration abilities in tissues as well as different mechanisms of biological interaction, resulting in different effects (Fig. 1) $[1,3,5]$

Occupational exposure to OR may be due to both natural and artificial sources; furthermore, the emissions can be classified as incoherent or coherent $[1,5]$.

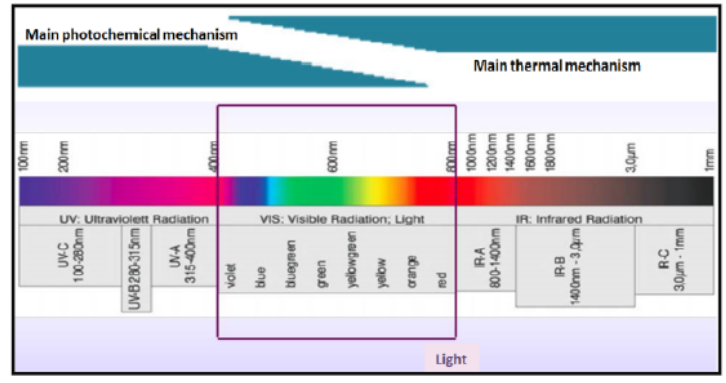

Fig. 1. The spectral composition of optical radiation and the different interaction mechanisms with the biologic tissues involved. 
The Sun is by large the main natural source of incoherent OR, and is the leading cause of occupational exposure for millions of outdoor workers worldwide. Solar radiation reaching the earth surface include the whole spectrum of OR, with the exception of UVC absorbed by the atmosphere [3, 5]. The most diffused sources of OR, both natural and artificial, emit incoherent radiations; examples are welding equipment, illumination systems, industrial machineries for photo-lithography, infrared based heating and drying systems etc. Coherent ORs, with phases of two or more waves representing the radiation differing by a known constant, are emitted by LASERs, having a huge and constatly increasing number of different applications. A non-exhaustive list of the main occupational sources of OR exposure of interest in occupational health and safety is presented in Table I.

Due to low penetration, the main targets of OR adverse health effects are the eye and the skin $[3,5]$. As introduced before, different OR bands have different mechanisms of biological interaction (Fig. 1), that can be classified as:

- Thermal mechanisms, characteristic of infrared radiation and of part of visible wavelength, mainly in the red

- Photochemical mechanisms, induced by the ultraviolet wavelengths and shorter wavelength of the visible, mainly in the blue $[1,5]$.

TABLE I. NON EXHAUSTIVE LIST OF WORK ACTIVITIES/POSSIBLE OCCUPATIONAL SOURCES, INDUCING A POTENTIAL RELEVANT EXPOSURE TO OPTICAL RADIATION

\begin{tabular}{|c|c|}
\hline $\begin{array}{l}\text { Wavelength } \\
\text { region }\end{array}$ & Work activities/sources inducing potential exposure \\
\hline UVC & $\begin{array}{l}\text { Germicidal sterilisation, fluorescent lamps (for labs), } \\
\text { photolithography, ink curing, welding, gas LASER } \\
\text { (Argon fluoride - ArF, Krypton fluoride - KrF) }\end{array}$ \\
\hline UVB & $\begin{array}{l}\text { Solar radiation (SR), sunbeds operators, phototherapy, } \\
\text { fluorescent lamps (for labs), photolithography, germicidal } \\
\text { lamps, ink curing, welding, gas LASER (Xenon chloride - } \\
\text { XeCl ), liquid (dye) LASER }\end{array}$ \\
\hline UVA & $\begin{array}{l}\text { SR, sunbeds operators, photolithography, phototherapy, } \\
\text { germicidal lamps, ink curing, welding, insect traps, } \\
\text { fluorescent lamps (for labs), heating/ drying applications, } \\
\text { welding, gas LASER (Nitrogen -N, Xenon fluoride - } \\
\text { XeF), liquid (dye) LASER }\end{array}$ \\
\hline Visible & $\begin{array}{l}\text { SR, area and task lighting, indicator lamps and traffic } \\
\text { signals, hair and thread vein removal, ink curing, insect } \\
\text { traps, photolithography, photocopying, projection, TV } \\
\text { and PC screens, sunbeds operators, heating/drying } \\
\text { applications, welding, gas LASER (Helium Neon - HeNe, } \\
\text { Helium Cadmium - HeCd, Argon Ion - Ar, Krypton Ion - } \\
\text { Kr), solid state LASER (Ruby, Neodymium: YAG - } \\
\text { Nd:YAG), semi-conductor LASER (Gallium nitride - } \\
\text { GaN, Gallium Aluminum Arsenide - GaAlAs), liquid } \\
\text { (dye) LASER }\end{array}$ \\
\hline IRA & $\begin{array}{l}\text { SR, area and task lighting, surveillance illumination, } \\
\text { heating/drying applications, hair and thread vein removal, } \\
\text { communication systems based on IRA, welding, solid } \\
\text { state LASER (Neodymium: YAG - Nd:YAG, } \\
\text { Neodymium: Glass - Nd:Glass ), fibre LASER } \\
\text { (Ytterbium - Yb), thin disk LASER (Ytterbium: YAG - } \\
\text { Yb:YAG ), semi-conductor LASER (Indium gallium } \\
\text { arsenide phosphide - InGaAsP), liquid (dye) LASER }\end{array}$ \\
\hline IRB & $\begin{array}{l}\text { SR, heating/drying applications, communication systems } \\
\text { based on IRB, area and task lighting, welding semi- } \\
\text { conductor LASER (Indium gallium arsenide phosphide - } \\
\text { InGaAsP), liquid (dye) LASER }\end{array}$ \\
\hline IRC & $\begin{array}{l}\text { SR, heating/drying applications, communication systems } \\
\text { based on IRB, welding, gas LASER (Carbon dioxide - } \\
\text { CO2), slab LASER (Carbon dioxide - CO2- Laser crystal) }\end{array}$ \\
\hline
\end{tabular}

Considering thermal mechanisms, the biological effect is due to the absorption of photons, increasing kinetic energy and inducing tissue heating. This effect is not cumulative, and has threshold because, if the increase of the temperature is not sufficient to induce a sudden damage of tissue components (e.g. protein denaturation), the heat is dissipated with no consequences. For these reasons OR responsible of thermal effects, as infrared, are mainly associated to acute effects as burns; also effects as cataract, possibly appearing in longer time, are related to a sequence of acute damages along time (Tab. II) $[3,5]$. On the other hand, photochemical mechanism is the consequence of the absorption of photons by targeted molecules (i.e. chromophores), inducing specific chemical reactions, and consequently determining various effects in the surrounding tissue (e.g. inflammation). Photochemical effects may be both acute, due to an intense reaction in case of high exposures in short time (e.g. sunburns), or long-term due to the additional photochemical alterations acquired over time (e.g. photoaging or cancer). Notably, due to the mechanism involved, also acute effects, as skin burns, don't appear immediately, but have a latency of some hours. A summary of the adverse health effects to the eye and to the skin related to OR exposure is reported in Table II [1, 3, 5]. Within the OR spectrum the UV component is of particular relevance, as it can induce the most severe adverse effects (e.g. is a recognized carcinogenic agent classified in group 1 by the International Agency for Research on Cancer as well as by other Agencies). Due to the relatively low penetration ability, main targets in humans' bodies are the eye and the skin, even if other effects, e.g. to the immune system, are described. UVR can induce short term photochemical effects, e.g. photo-keratitis and skin burns, and long term effects in the eyes, as cataract $[6,7]$, pterygium [8] and possibly macular degeneration [9], as well as rare eye tumours as cornea and conjunctiva's carcinomas and uveal melanoma [3,5], and in the skin, as photoaging, actinic keratosis, keratinocyte carcinomas (basal and squamous cell carcinomas), and skin melanoma [3, 10, 11]. A possible role in the development of photochemical effects has been hypothesized also for the highly energetic blue component of visible light [1] (Table II).

TABLE II. HEALTH EFFECTS OF OPTICAL RADIATION

\begin{tabular}{|c|c|c|}
\hline & Eyes effects & Skin effects \\
\hline $\begin{array}{l}\text { UVR (mainly } \\
\text { photochemical } \\
\text { effects) }\end{array}$ & 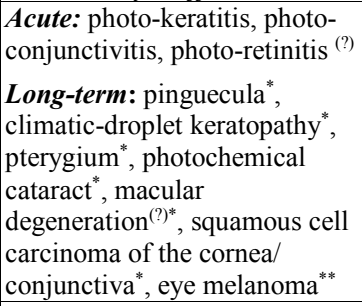 & $\begin{array}{l}\text { Acute: photo-chemical } \\
\text { skin burns, photo- } \\
\text { dermatoses } \\
\text { Long-term: photo-aging*, } \\
\text { actinik keratoses", non- } \\
\text { melanoma skin cancers } \\
\text { (basal and squamous cell } \\
\text { carcinomas), cutaneous } \\
\text { malignant melanoma }\end{array}$ \\
\hline $\begin{array}{c}\text { Visible } \\
\text { (possible both } \\
\text { photochemical } \\
\text { \& thermal } \\
\text { effects) }\end{array}$ & $\begin{array}{l}\text { Acute: } \text { photo-retinitis }{ }^{\S} \text {, retinal } \\
\text { burn }^{\S \S} \\
\text { Long-term: } \text { macular } \\
\text { degeneration }^{(?)^{*}}\end{array}$ & $\begin{array}{l}\text { Acute: photo-dermatoses } \\
\text { Long-term: photo-aging } \\
(?)^{*}\end{array}$ \\
\hline $\begin{array}{c}\text { IR (mainly } \\
\text { thermal } \\
\text { effects) }\end{array}$ & $\begin{array}{l}\text { Acute: retinal burn } \\
\text { Long-term: thermic cataract }\end{array}$ & $\begin{array}{l}\text { Acute: } \text { skin thermal burn } \\
\text { Long-term: chronic } \\
\text { erythema \& telangiectasia }\end{array}$ \\
\hline
\end{tabular}

(?) proposed effect, still not demonstrated with sufficiently adequate level of evidence in humans; * effects mainly demonstrated as associated to solar radiation exposure; ** effect mainly demonstrated as associated to welding activities $\$$ effect associated to warm light 


\section{ELECTROMAGNETIC FIELDS}

Electromagnetic fields (EMFs) are almost ubiquitous, so nowadays all (or almost all) workers all around the world are exposed to an enormous variety of environmental and occupational sources. This, of course, raises the problem of an adequate definition of "exposed worker". Even if a shared definition is not available, in principle it refers to a worker whose occupational exposure to EMF is a specific risk to health and safety. Usually the risk can be induced by EMF exposures exceeding the levels occurring in the general population, but in some (presumably few) specific individuals with a higher susceptibility, also lower levels may pose an occupational risk (see below). As for OR, also for EMFs the known mechanisms for biological interaction and, consequently, the effects are different depending on the frequency. For the purposes of this manuscript, we apply here a simplified classification of EMF, and we address the main problems related to occupational exposure to static magnetic fields (SMF), extremely-low frequency electric or magnetic fields (ELF), intermediate frequency EMF (IFEMF) and high frequency EMF (HF-EMF), including radiofrequency (RF), microwaves, millimeter and terahertz waves (Fig. 2) [2, 12-14].

In Table III, adapted from the non-binding guide for the application of the European Directive 2013/35/EU [2], it is presented a non-exhaustive list of work activities and occupational sources of EMF inducing exposure to be considered for occupational health and safety purposes. It should be noted that in Table III sources are not classified according to the frequency range as in various cases emission can involve different bands of EMF spectrum, as e.g. in welding or MRI, even if for other sources the emission are mainly limited to a specific band, as e.g. electrical distribution or transmissions, respectively emitting in the ELF and RF range [12-17]. Of course, not all the potential exposures listed in Table III in usual conditions can induce a significant occupational risk; examples are wireless communications and various equipment in the office. On the other hand, as previously introduced, most may represent a risk at least for workers having pathological or physiological conditions inducing a higher susceptibility to EMFs adverse effects, defined "workers at particular risk" in the abovementioned EU Directive, [2]. Examples are persons with active implanted medical devices (AIMD) (e.g. pacemakers and implantable cardioverter-defibrillators): in these cases potentially relevant problems in the functioning of the devices may appear due to electro-magnetic interference (EMI). The problem is that in some (presumably very rare) cases EMI can be induced by EMFs not exceeding the levels found in the population, as can happens in case of some pacemakers in unipolar sensing configuration. Another condition explicitly considered at higher risk in the European Directive is pregnancy. In other examples presented in Table III the EMF source usually induce high levels, potentially representing an occupational risk in case of inadequate working conditions, e.g. close proximity of the operators to MRI scanners, industrial electrolysis plants, induction heating or soldering devices, broadcasting systems and devices, etc. [2, 12-14].

\begin{tabular}{|c|c|c|c|}
\hline Classification & Sub-class/division & Abbreviation & Frequency \\
\hline Static fields & $\begin{array}{l}\text { Static electric fields } \\
\text { Static magnetic fields }\end{array}$ & $\begin{array}{l}\text { SEF } \\
\text { SMF }\end{array}$ & $\mathrm{OHz}$ \\
\hline Low frequencies & $\begin{array}{l}\text { Extremely low frequency } \\
\text { electric or magnetic fields } \\
\text { Intermediate frequency electromagnetic fields }\end{array}$ & \begin{tabular}{|l} 
ElF EF \\
ELF MF \\
IF EMF
\end{tabular} & $\begin{array}{l}\mathrm{I}-<300 \mathrm{~Hz} \\
300 \mathrm{~Hz}<<100 \mathrm{kHz}\end{array}$ \\
\hline High frequencies & \begin{tabular}{|l} 
Radiofrequency electromagnetic fields ("radiowaves") \\
Microwaves \\
Millimeter waves \\
Terahertz waves
\end{tabular} & $\begin{array}{l}\text { RF EMF } \\
\text { MW } \\
\text { MMW } \\
\text { THz }\end{array}$ & 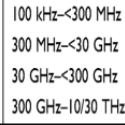 \\
\hline
\end{tabular}

Fig. 2. Simplified classification of electro-magnetic fields

TABLE III. EXAMPLES OF WORK ACTIVITIES/POSSIBLE OCCUPATIONAL SOURCES INDUCING A POTENTIAL RELEVANT EXPOSURE TO

ELECTROMAGNETIC FIELDS ADAPTED FROM THE NON-BINDING GUIDE [2]

\begin{tabular}{|l|}
\hline \multicolumn{1}{|c|}{ Type of equipment or workplace } \\
\hline Wireless communications \\
\hline Phones, cordless (including base stations for cordless phones), mobiles \\
\hline Office \\
\hline $\begin{array}{l}\text { Audio-visual equipment containing radiofrequency transmitters, Office } \\
\text { equipment (e.g. photocopiers, paper shredders, electrical staplers) }\end{array}$ \\
\hline Infrastructure (buildings and grounds) \\
\hline Base station antennas, Garden appliances \\
\hline Electrical supply \\
\hline $\begin{array}{l}\text { Electrical installations, Generators and emergency generators, } \\
\text { Inverters, including those on photovoltaic systems }\end{array}$ \\
\hline Light industry \\
\hline $\begin{array}{l}\text { Arc welding processes, manual (including MIG, MAG, TIG), Dielectric } \\
\text { heating and welding, Magnetizer/demagnetizers, industrial (including } \\
\text { tape erasers) }\end{array}$ \\
\hline Heavy industry \\
\hline Industrial electrolysis, Furnaces, arc melting \\
\hline Construction \\
\hline $\begin{array}{l}\text { Construction equipment (e.g. concrete mixers, vibrators, cranes, etc), } \\
\text { Microwave drying, in construction industry }\end{array}$ \\
\hline Medical \\
\hline $\begin{array}{l}\text { Magnetic Resonance Imaging (MRI), Other medical equipment using } \\
\text { EMF for diagnosis and treatment (for example, short wave diathermy, } \\
\text { transcranial magnetic stimulation) }\end{array}$ \\
\hline Transport \\
\hline $\begin{array}{l}\text { Motor vehicles and plant, Radar, air traffic control, military, weather and } \\
\text { long range, Trains and trams, electrically driven }\end{array}$ \\
\hline
\end{tabular}

Regarding the possible adverse effects related to occupational EMF exposure to be considered in health surveillance (HS), a premise is that, at least in Europe, according to the European Directive 2013/35/EU currently only short term direct biophysical and indirect effects are considered, as available scientific evidence is adequate and pathogenetic mechanisms in humans are known [2, 12-14]. For other suggested long term effects, as e.g. leukemia for ELF and brain cancer for exposure to RF, data on causal relationhship with EMF exposure in workers are considered currently inadequate. Accordingly, until adequate demonstrations of an association, including coherent mechanisms, are available, these effects are not explicitly taken into account in HS $[2,12-14]$. There is to observe that the position of the EU Commission regarding long term EMF effects is coherent with that of several recognized national and international institutions and organizations as e.g.: Advisory Group on Non-Ionising Radiation, Agence nationale de sécurité sanitaire de l'alimentation, de l'environnement et du travail, the American Cancer Society, Australian Radiation Protection and Nuclear Safety Agency, Comité Científico Asesor en Radiofrecuencias y Salud, Federal Communications Commission, Food and 
Drug Administration, Health Council of the Netherlands, International Agency for Cancer Research, International Commission on Non-Ionizing Radiation Protection, Istituto Superiore di Sanità, New Zealand Ministry of Health, Public Health England, Swedish Radiation Safety Authority's Scientific Council on Electromagnetic Fields, and others.

According to the abovementioned EU approach, EMFrelated effects possibly expected in exposed workers are: a) direct biophysical effects caused in the human body by its presence within an EMF; and b) indirect effects, induced by the presence of an object in the EMF (the object may be placed also inside the human body, as it happens for medical devices) (Tab. IV). The mechanisms involved for direct effects are non-thermal ones for static and LF fields and thermal mechanisms for HF, while for IF both are possible. Indirect effects can be potentially related to all EMF frequencies (Tab. IV) [2, 12-14].

A further classification of EMF related direct effects introduced by the EU Directive is into "sensory" and "health effects". The former are transient and reversible, and can be considered somewhat minor effects not having usually any adverse health impact, even if an increased risk of workrelated injuries cannot be excluded. These effects are mainly related e.g. to relevant SMF and ELF-EMF exposures, as a consequence of a stimolous involving nervous systems and sensory organs, based on current induction (e.g. vertigo, nausea, eye lamps) (Tab. V) [2, 12, 13, 17]. EMF-related "health effects" are more severe compared to sensory ones, and they usually appear only in case of overexposure to EMF highly above the occupational limits. For SMF and ELF-EMF the effects are associated to non-thermal mechanisms (e.g. heart arrhythmia), while for HF-EMF to thermal mechanisms (as burns) (Tab V) [2, 14, 18, 19].

TABLE IV. SUMMARY OF DIRECT AND INDIRECT EFFECTS ASSOCIATED TO EMF EXPOSURE AND OF THE MECHANISMS INVOLVED

\begin{tabular}{|c|c|}
\hline Direct Biophysical Effects & Indirect effects \\
\hline $\begin{array}{c}\text { Non-thermal effects, related to static, } \\
\text { low and intermediate frequency fields }\end{array}$ & $\begin{array}{c}\text { Interference } \text { with medical } \\
\text { electronic equipment and } \\
\text { E.g. limb currents, stimulation of } \\
\text { devices, including cardiac } \\
\text { inducing temporary annoyance or } \\
\text { pacemakers and other implants } \\
\text { leading to a possible detrimental effect of } \\
\text { cognition or of other brain or muscle } \\
\text { functions, or inducing safety risks, etc }\end{array}$ \\
$\begin{array}{c}\text { Thermal effects, related to high and } \\
\text { intermediate frequency fields }\end{array}$ & $\begin{array}{c}\text { Contact currents } \\
\text { E.g. skin burns, cataract, etc }\end{array}$ \\
\hline
\end{tabular}

TABLE V. SUMMARY OF THE EFFECTS ASSOCIATED TO VARIOUS EMF FREQUENCIES CLASSIFIED AS "SENSORY" AND "HEALTH" EFFECTS

\begin{tabular}{|c|c|c|}
\hline EMF type & Sensory effects & Health effects \\
\hline $\begin{array}{c}\text { Static } \\
\text { magnetic field }\end{array}$ & $\begin{array}{c}\text { Vertigo, nausea, } \\
\text { metallic taste }\end{array}$ & $\begin{array}{c}\text { Altered blood flow in limbs, altered } \\
\text { brain / heart function }\end{array}$ \\
\hline $\begin{array}{c}\text { Low } \\
\text { frequency } \\
\text { fields }\end{array}$ & $\begin{array}{c}\text { Magnetophosphenes, } \\
\text { minor changes in brain } \\
\text { function }\end{array}$ & $\begin{array}{c}\text { Pain or tingling sensation due to } \\
\text { stimulation of nerves, involuntary } \\
\text { contractions of muscles, alterations } \\
\text { of cardiac rhythm }\end{array}$ \\
\hline $\begin{array}{c}\text { Intermediate } \\
\text { frequency } \\
\text { fields }\end{array}$ & $\begin{array}{c}\text { Effects of both high } \\
\text { and low frequencies } \\
\text { can be experienced }\end{array}$ & $\begin{array}{c}\text { The effects of both high and low } \\
\text { frequencies can be experienced }\end{array}$ \\
\hline $\begin{array}{c}\text { High } \\
\text { frequency } \\
\text { fields }\end{array}$ & $\begin{array}{c}\text { Microwave auditory } \\
\text { effects }\end{array}$ & $\begin{array}{c}\text { Excessive increase in temperature } \\
\text { or thermal burns over the whole } \\
\text { body or in specific areas, thermal } \\
\text { damage at the eyes (possibility of } \\
\text { thermal cataracts) or skin }\end{array}$ \\
\hline
\end{tabular}

\section{NON-IONIZING RADIATION: WORKERS AT} PARTICULAR RISK AND HEALTH SURVEILLANCE

According to the International Labour Office (ILO), health surveillance (HS) involves procedures and investigations to assess workers' health, in order to identify any abnormality possibly associated to a recognized workrelated risk in exposed workers [20]. HS involves the review of the health records and any other opportune medical examinations needed [20]. Questionnaires may be useful tools, better if validated in the national language [21]. All the investigations chosen for HS should be supported by an adequate level of scientific evidence, proving the applicability of the procedure for the specific purposes. According to the Code of Ethics of the International Commission on Occupational Health (ICOH) [22], the HS contents can include biological tests and other investigations, when they are chosen for their validity and relevance with respect to the occupational risks, avoiding investigations that don't fulfill these criteria.

Considering the specific case of NIR exposure, the abovementioned criteria for HS seem applicable to OR exposure, while a reliable application for EMF-related occupational risks may present some possible issues, as better discussed below. Nevertheless, in both the cases adequate and updated skills in this specific field is needed for occupational physicians involved in HS. Considering this specific aspect we have to admit that we are not completely confident that NIR occupational risk, health effects and prevention topics are sufficiently covered during the training of all occupational medicine specialists. In any case, in specific situations, on an individual basis, occupational physicians competence may require to be integrated by investigations and/or consultation of other medical specialists.

For both the NIR risks a special attention during HS, as well as during other preventive activities (e.g. risk evaluation, definition of technical and organizational preventive measures, workers' training, etc), should be deserved to the possible occurrence of workers "belonging to particularly sensitive risk groups" or "at particular risk", as respectively indicated in the European Directives, i.e. $2006 / 25 / \mathrm{EU}$ for the prevention of the risk related to artificial optical radiation exposure [1] and 2013/35/EU for the prevention of the risk related to EMF exposure [2]. For simplicity, we will adopt here the latter term (workers at particular risk) for both the NIR risks: in the Table VI is presented a non-exhaustive list of conditions possibly involving a particular risk in case of OR and EMF exposure (Tab. VI) [1-3, 5, 12-14]. It should be noted that for EMF the conditions of particular risk reported in Table VI are almost defined in the EU Directive 2013/35/EU and, according to the adverse effects previously discussed and to the current scientific literature, no other conditions of particular susceptibility to the EMF risk have been demonstrated [2, 12-14]. In the case of OR no specific indications are explicitly included in the Directive 2006/25/EU, so in the Table we report conditions of particular susceptibility, mainly for eye and skin OR-related adverse effects, according to the main relevant scientific evidences $[1,3,5]$. 
TABLE VI. CATEGORIES OF WORKERS AT PARTICULAR RISK OF OCCUPATIONAL NON-IONIZING RADIATION EXPOSURE AND EXAMPLES OF CONDITIONS INDUCING A PARTICULAR RISK

\begin{tabular}{|c|c|}
\hline Optical Radiation & Electromagnetic fields \\
\hline $\begin{array}{l}\text { Conditions related to a possible } \\
\text { increased risk of UVR-induced } \\
\text { skin effects: workers affected by } \\
\text { collagen diseases and other photo- } \\
\text { induced or photo-aggravated skin } \\
\text { diseases (e.g. psoriasis, xeroderma } \\
\text { pigmentosum, etc), albino subjects } \\
\text { and other workers with fair skin } \\
\text { photo-types (e.g. Fitzpatrick skin } \\
\text { photo-type } 1 \text { or 2), workers with pre- } \\
\text { malignant or malignant skin lesions, } \\
\text { workers undergoing long-term } \\
\text { therapeutic treatments with photo- } \\
\text { sensitizing drugs (condition possibly } \\
\text { relevant also for photo-dermatoses } \\
\text { related to visible radiation) }\end{array}$ & $\begin{array}{l}\text { Workers wearing active implanted } \\
\text { medical devices (AIMD): workers } \\
\text { with cardiac pacemakers, } \\
\text { cardioverter-defibrillators, cochlear } \\
\text { implants, brainstem implants, inner } \\
\text { ear prostheses, neurostimulators, } \\
\text { retinal encoders, implanted drug } \\
\text { infusion pumps }\end{array}$ \\
\hline $\begin{array}{l}\text { Conditions related to a possible } \\
\text { increased risk of optical radiation } \\
\text { induced eye effects: workers } \\
\text { affected by iris alterations (e.g. } \\
\text { coloboma, aniridia), pupil alterations } \\
\text { (e.g. tonically dilated pupil, } \\
\text { mydriasis), retinal alterations (e.g. } \\
\text { drusen), lens alterations (lens } \\
\text { opacities, previous cataracts, } \\
\text { artificial intraocular lens) }\end{array}$ & $\begin{array}{l}\text { Workers wearing passive } \\
\text { implanted medical devices } \\
\text { containing metal: artificial joints, } \\
\text { pins, plates, screws, surgical clips, } \\
\text { aneurism clips, stents, heart valve } \\
\text { prostheses (including orthopaedic, } \\
\text { eye/retinal prostheses and others), } \\
\text { annuloplasty rings, metallic } \\
\text { contraceptive implants, penile } \\
\text { implants and cases of AIMD }\end{array}$ \\
\hline \multirow{2}{*}{$\begin{array}{l}\text { Other conditions: workers affected } \\
\text { by epilepsy for exposure to } \\
\text { intermittent lights ( } 15-25 \text { flashes per } \\
\text { second); pregnant workers in } \\
\text { particular, but not limited to, for } \\
\text { infrared related thermal effects, } \\
\text { underage workers in general. }\end{array}$} & $\begin{array}{l}\text { Workers wearing body-worn } \\
\text { medical devices: workers with } \\
\text { external hormone infusion pumps, } \\
\text { with hearing aids, with continuous } \\
\text { glucose monitoring systems and with } \\
\text { metallised drug-delivery patches }\end{array}$ \\
\hline & $\begin{array}{c}\text { Other categories not including the } \\
\text { wearing of medical devices: } \\
\text { pregnant workers }\end{array}$ \\
\hline
\end{tabular}

Moving now more specifically to EMF, according to the European legislation HS of exposed workers is mandatory as required in the Directive 2013/35/EU. Furthermore, as the risk assessment and the implementation of preventive and protective measures, HS for EMF exposure has to take into account also the "workers at particular risk", explicitly listing in this group the workers with implanted medical devices and pregnant workers; a more detailed list of conditions possibly inducing a particular risk in case of EMF exposure is presented in Table VI; to date no other conditions have been adequately demonstrated [2, 12 - 14]. At least in Europe, the objective of the HS is the protection from the risks related to the known direct biophysical effects and the indirect effects of EMF (Tab. IV). Accordingly, objective of the HS is the prevention, highlighting and early diagnosis of all established direct effects, including sensory effects (as vertigo nausea, etc.), the stimulation of muscles, nerves or sensory organs, and any thermal effect [2]. Usually these effects are not expected below the occupational limits, and are possible only in case overexposure to high EMF levels [13, 17-19]. Nevertheless, it should be noted that sensory effects do not necessarily represent a health risk, as they are usually transient and totally reversible, even if they may represent a risk of accidents $[12,13]$. The other specific objective of HS is the prevention of EMF-related indirect effects in workers at particular risk, and especially those with implanted or body-worn active medical devices. In this case, electro-magnetic interference problems with the functions of the devices may be possible also in case of quite low exposure levels, expected also in case of proximity to EMF sources usually considered safe for the majority of the subjects [2, 12-14]. According to these considerations, HS of EMF exposed workers is therefore mainly aimed to evidence the occurrence of clinical sensory symptoms possibly related to EMF and the existence of conditions of particular risk. Considering the previously introduced general indications for HS according to ILO and ICOH principles, specific laboratory tests for the prevention of EMF effects are not required, except on individual clinical basis. Furthermore, a routine periodic HS of healthy subjects working in environments where the levels of occupational exposure to EMF are expected to be low, as e.g. offices but also the use of the majority of the electrical utensils, seems not advisable, and only a preventive investigation for detecting possible conditions of particular susceptibility to the risk, with an effective information of all the workers on these conditions, to be periodically repeated, seems an appropriate preventive action.

Specifically considering the occupational OR exposure, according to the European legislation example we have two possible scenarios for HS: mandatory for artificial radiation, including incoherent sources and LASERs, in case of presence of a health risk based on the risk evaluation, while for exposure to natural occupational sources, as is the case of solar radiation in outdoor workers, currently in Europe there are no specific indications for a mandatory $\mathrm{HS}[1,3,5]$. Nevertheless, considering the number of workers exposed, the high exposure levels, especially to UVR, expected during outdoor work [4], the relevancy of the possible adverse effects, and the expected number of cases $[3,4,6,8,9,11]$ it seems absolutely necessary to include solar OR among the occupational risk to be evaluated in outdoor workers and, according to the results, decide on the need of an appropriate HS to be implemented. The HS is aimed to the prevention and the early diagnosis of adverse effects, mainly to the eye and the skin, with particular consideration for UVR-induced effects, including skin cancers (i.e. keratinocytes carcinomas - basal and squamous cell carcinoma - and malignant melanoma), that are currently the most frequent neoplasms in Caucasian individuals. Specific attention is needed for the screening of the workers affected by conditions inducing a particular susceptibility, as the ones reported in Table VI, and for an adequate prescription of effective preventive measures. A a consequence, HS programs should include both pre-employment and periodic medical examinations of the exposed workers. Specific medical examinations, e.g. dermatologic and/or ophthalmologic, should be requested on individual basis in case of need. Moreover, it should be remembered that keratinocytes carcinomas are recognized occupational diseases in UVR exposed outdoor workers in various countries, even if they are largely under-reported to the workers' compensation national Authorities [3, 4].

\section{CONCLUSIONS}

Occupational exposure to Non-Ionizing radiation, including EMF and OR, is almost ubiquitous. In all NIR exposed workers the occupational risk should be evaluated and, based on the results, specific health surveillance programs aimed to the prevention and early detection of possible health effects should be implemented. These 
activities should consider also the "workers at particular risk".

In the case of EMF the currently recognized effects are short-term direct biophysical effects, related to both nonthermal and thermal mechanisms, and indirect effects. Direct biophysical effects are usually induced by high exposures, while indirect effects, as interference with active implanted medical devices (AIMD), can possibly occur also in case of lower exposure levels. Optical radiation may be related to both artificial and natural sources, but by large the main exposure is due to solar radiation, often under-considered but causing significant adverse health effects including, but not limited to, skin cancers, mainly related to the photochemical actions of the UV component.

For workers exposed to EMF currently there is no agreement on the more appropriate specific contents of HS, but at least the collection of symptoms possibly induced by the exposure, and a screening of the conditions inducing a particular risk, as in the case of workers with AIMD, should be performed before of the employment, and periodically repeated. Similar criteria should be applied also for OR exposed workers; in this case, subjects with conditions as e.g. a fair skin photo-type (i.e. a Fitzpatrick skin photo-type 1 or 2) or workers with some iris or lens alterations should be screened, and the occurrence of OR induced effects (mainly UV related) as skin erythema, burns, photoaging, or photokeratoconjunctivitis, pterygium or lens opacities should be investigated. In this case, it should be also remembered that epidemiological data support the occurrence of a large number of related diseases, particularly skin cancers, in UVR exposed workers, and that these diseases are recognized occupational diseases in many countries, but are frequently underreported to national compensation authorities.

A last consideration is that HS of NIR exposed workers requires adequate and updated skills of the occupational physicians in this specific field; we wonder whether, to date, these skills are always sufficiently covered in the training of occupational medicine specialists, and accordingly we recommend more attention to this risk in the future.

\section{REFERENCES}

[1] European Commission, (2011) Non-binding guide to good practice for implementing Directive 2006/25/EC - Artificial Optical Radiation. [Online]. Available:

www.av.se/globalassets/filer/publikationer/foreskrifter/optiskstralning-eu-guide-eng.pdf

[2] European Commission, (2014) Non-binding guide to good practice for implementing Directive 2013/35/EU - Electromagnetic Fields, Volume 1: Practical Guide. [Online]. Available: https://op.europa.eu/en/publication-detail/-/publication/c6440d358775-11e5-b8b7-01aa75ed71a1

[3] A. Modenese, L. Korpinen, and F. Gobba, "Solar Radiation Exposure and Outdoor Work: An Underestimated Occupational Risk," Int J Environ Res Public Health., vol. 15(10), pp. E2063, September 2018.

[4] F. Gobba, A. Modenese, and S.M. John, "Skin cancer in outdoor workers exposed to solar radiation: a largely underreported occupational disease in Italy," J. Eur. Acad. Dermatol. Venereol., vol. 33(11), pp. 2068-2074, December 2019.

[5] International Commission on Non-Ionizing Radiation Protection, "Icnirp state-ment - protection of workers against ultraviolet radiation,” Health. Phys., vol. 99, pp. 66-87, July 2010.

[6] A. Modenese, and F. Gobba, "Cataract frequency and subtypes involved in workers assessed for their solar radiation exposure: a systematic review," Acta. Ophthalmol., vol. 96(8), pp. 779-788, December 2018

[7] T. Tenkate, B. Adam, R.H. Al-Rifai, B.R. Chou, F. Gobba, et al., "WHO/ILO work-related burden of disease and injury: Protocol for systematic reviews of occupational exposure to solar ultraviolet radiation and of the effect of occupational exposure to solar ultraviolet radiation on cataract," Environ Int,vol.125,pp.542-53, 2019

[8] A. Modenese, and F. Gobba, "Occupational Exposure to Solar Radiation at Different Latitudes and Pterygium: A Systematic Review of the Last 10 Years of Scientific Literature," Int. J. Environ. Res. Public. Health., vol. 15(1), pp. pii: E375, December 2017.

[9] A. Modenese, and F. Gobba, "Macular degeneration and occupational risk factors: a systematic review," Int. Arch. Occup. Environ. Health., vol. 92(1), pp. 1-11, January 2019.

[10] M. Silva Paulo, B. Adam, C. Akagwu, I. Akparibo, R.H. Al-Rifai, S. Bazrafshan, et al., "WHO/ILO work-related burden of disease and injury: Protocol for systematic reviews of occupational exposure to solar ultraviolet radiation and of the effect of occupational exposure to solar ultraviolet radiation on melanoma and non-melanoma skin cancer," Environ. Int., vol. 126, pp. 804-815, May 2019.

[11] A. Modenese, F. Farnetani, A. Andreoli, G. Pellacani, and F. Gobba, "Questionnaire-based evaluation of occupational and nonoccupational solar radiation exposure in a sample of Italian patients treated for actinic keratosis and other non-melanoma skin cancers," J Eur Acad Dermatol Venereol., vol. 30(supp.3), pp. 21-26, April 2016.

[12] International Commission on Non-Ionizing Radiation Protection. "Guidelines for limiting exposure to time-varying electric and magnetic fields (1 Hz to $100 \mathrm{kHz}) "$, Health. Phys., vol. 99(6), pp. 818-836, December 2010.

[13] International Commission on Non-Ionizing Radiation Protection, "Guidelines for limiting exposure to electric fields induced by movement of the human body in a static magnetic field and by timevarying magnetic fields below $1 \mathrm{~Hz}$ ", Health. Phys., vol. 106(3), pp. 418-425, March 2014

[14] International Commission on Non-Ionizing Radiation Protection, "Guidelines for Limiting Exposure to Electromagnetic Fields (100 kHz to $300 \mathrm{GHz}$ )", Health. Physics., March 2020, to be published.

[15] F. Gobba, A. Bargellini, G. Bravo, M. Scaringi, L. Cauteruccio, and P. Borella, "Natural killer cell activity decreases in workers occupationally exposed to extremely low frequency magnetic fields exceeding 1 microT", Int. J. Immunopathol. Pharmacol., vol. 22(4), pp. 1059-66, December 2009.

[16] F. Gobba, G. Bravo, P. Rossi, G. M. Contessa, and M. Scaringi, "Occupational and environmental exposure to extremely low frequency-magnetic fields: a personal monitoring study in a large group of workers in Italy", J. Expo. Sci. Environ. Epidemiol., vol. 21(6), pp. 634-645, December 2011.

[17] G. Zanotti, G. Ligabue, L. Korpinen, and F. Gobba, "Subjective symptoms in Magnetic Resonance Imaging operators: prevalence, short-term evolution and possible related factors", Med. Lav., vol. 107(4), pp. 263-70, July 2016.

[18] B. Hocking, and F. Gobba, "Medical aspects of overexposures to electromagnetic fields", J. Health. Saf. Environ., vol. 27(3), pp. 185195, 2011.

[19] Institute of Electrical and Electronics Engineers, "Medical aspects of radiofrequency radiation overexposure", Health. Phys., vol. 82(3), pp. 387-391, March 2002

[20] International Labour Office, (1998) Occupational Safety and Health Series $n^{\circ}$ 72. Technical and ethical guidelines for workers' health surveillance. [Online]. Available: www.ilo.org/wcmsp5/groups/public/---ed protect/---protrav/--safework/documents/normativeinstrument/wcms_177384.pdf

[21] F. Gobba, R. Ghersi, S. Martinelli, A. Richeldi, P. Clerici, P. Grazioli, "Italian translation and validation of the Nordic IRSST standardized questionnaire for the analysis of musculoskeletal symptoms", Med. Lav., vol. 99(6), pp. 424-43, December 2008.

[22] International Commission on Occupational Health, (2014) International code of ethics for occupational health professionals. [Online]. Available:

www.icohweb.org/site new/multimedia/core documents/pdf/code et hics_eng_2012.pdf 